\title{
Assessment of frictional resistance of granite rock joints with reference to weathering
}

\author{
Bikash Kumar Ram and Arindam Basu \\ Indian Institute of Technology Kharagpur \\ Kharagpur, India \\ bikashram@gg.iitkgp.ernet.in
}

\begin{abstract}
Shearing resistance of rock joints is considered as one of the key aspects of rock masses as it is related to the stability of rock mass particularly at shallow surface condition. The shear behaviour of rock joints depends upon a number of influencing parameters and weathering state of discontinuity surface is one of them. However, over the years of research, the said issue has not been explored much. Hence this research presents primary findings aimed to explore the shearing resistance of unfilled rock joints regarding granites of different weathering grades. Multistage CNL direct shear tests were performed on six natural granite rock joints of two different but adjacent weathering grades at three different normal stress conditions ranging between $0.21 \mathrm{MPa}-0.7 \mathrm{MPa}$. It should be noted that the weathering grade of discontinuity surface was categorized following the six-fold weathering grade classification scheme, which was also substantiated with Schimdt rebound values. The data obtained from shear test was analysed in terms of stress ratio and peak friction angle, which shows the adverse effect of weathering with increasing normal stress condition. However, at low normal stress condition, such consequences were not significant.
\end{abstract}

Keywords-frictional resistance of rock joint; weathering; peak friction angle; coefficient of friction

\section{I.INTRODUCTION}

Discontinuities such as joints, fractures, bedding planes are present inherently in rock masses. As it is well known that the chances of failure of intact rocks are minimal at shallow surface condition, it is the discontinuities that play an important role in controlling mechanical behavior of rock masses. Hence, the frictional/shearing resistance offered by such planes of weakness is considered as one of the major aspects in rock engineering environment (i.e. at shallow surface/near surface condition), in terms of stability of the rock masses and safe designing of engineering structures. However, the frictional resistance of rock joints itself is influenced by a number of factors such as magnitude of normal stress, joint roughness coefficient, joint compressive strength, weathering state of discontinuity, shearing rate, scale effect, degree of saturation, nature and thickness of infill material and so on [1]. Over the several decades, a number of research works were carried out in order to study the influence of individual factor or multiple factors controlling shear behavior considering fabricated surfaces made up of POP or cement, mimicked joint planes as well as natural joints by several researchers [1-15]. However, the influence of weathering on the shear strength/frictional resistance of natural unfilled joints does not seem to have been much explored. Hence, this research presents primary findings aimed to explore the shearing resistance of unfilled rock joints with reference to granites of different weathering grades.

\section{COLLECTION OF SAMPLES AND WEATHERING GRADE CATEGORIZATION}

Oriented block samples of granites with unfilled but weathered joints within were collected from the face of a quarry in Dahanimara village(N21028'46' 'E $86^{0} 45^{\prime} 27^{\prime}$ '), Nilgiri Block of Balasore District, Odisha. These rocks belong to Singhbhum Granite as far as geology of the area is concerned [16]. A view of of the exposure from where samples were collected is shown in Fig.1.

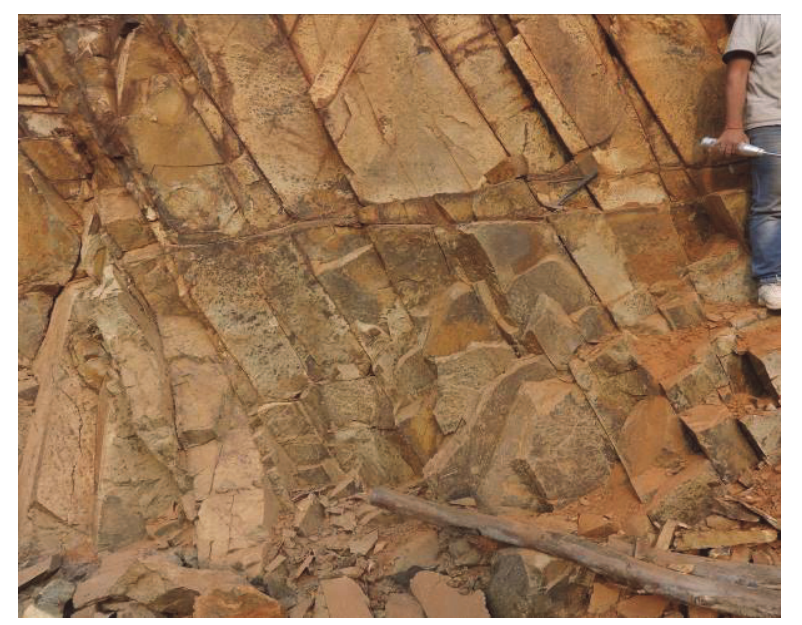

Fig.1.A view of exposure at Dahanimara from where jointed block samples were collected

Prior to cutting the samples, weathering grades of the joint surface materials were assigned following the six-fold classification schemes by ANON,1995[17] and ISRM, 2007[18]. This was substantiated quantitatively by rebound hammer test (impact energy $0.735 \mathrm{Nm}$ ). On this basis the investigated rock joints were assigned two different but adjacent weathering grades i.e. Grade- II (3 samples) and Grade- III (3 samples). 


\section{LABORATORY INVESTIGATIONS}

\section{A. Determination of JRC}

Joint roughness coefficient (JRC) is considered as one of the most important factor that influences the frictional resistance of rock joints. Hence, before performing direct shear tests, the joint roughness coefficient (JRC) was assigned to the joint surfaces. For this purpose, several parallel lines were drawn on the surface along the shear direction (taken as the dip direction of the joints in-situ), and the discontinuity surface irregularities were measured with the help of a digital dial-gauge (resolution $=0.01 \mathrm{~mm}$ ). Then the roughness profiles were drawn and JRC for each profile was calculated using $Z_{2}$ method as proposed by Myers, 1962[19] (equation 1) and $\mathrm{Yu}$ and Vayssade, 1991[20]. (equation 2).

$$
Z_{2}=\sqrt{\frac{1}{L} \int_{x=0}^{x=L}\left(\frac{d y}{d x}\right)^{2} d x}
$$

where $\mathrm{Z} 2$ is the root mean square, $\mathrm{L}$ is the length of the profile, $\mathrm{X}$ and $\mathrm{y}$ are equally spaced points along the profile on the $\mathrm{x}$ and $\mathrm{y}$ coordinates.

$$
\mathrm{JRC}=61.79\left(\mathrm{Z}_{2}\right)-3.47
$$

where JRC is the Joint Roughness Coefficient, Z2 is the root mean square.

In this study, mostly planer rock joint having JRC value 1-3 were considered. It should be noted that JRC for a particular joint surface was finally obtained by averaging JRC values for all profiles.

\section{B. Direct shear test and samples preparation}

The frictional resistance of natural rock joints is obtained by performing direct shear tests. So, in order to make the samples (with joint surface area of each block as $10-12 \times 8$ $10 \mathrm{~cm}^{2}$ ) ready for shear test, upper and lower blocks were encapsulated with the help of plaster of paris as well as cement- sand mixture in order to fit them inside the shear box of the direct shear test apparatus. Rock sample was kept 5-7 $\mathrm{mm}$ elevated from the encapsulated material. The area of the lower block joint surface was kept slightly larger than that of the upper one. An encapsulate shear sample was shown in Fig.2.

The shear test apparatus with the loading capacity of $100 \mathrm{kN}$ (i.e. both shear load and normal load) was used in this investigation (Fig.3). The horizontal and vertical displacements were recorded with the help of digital dial gauges $($ resolution $=0.01 \mathrm{~mm}$ ).

ISRM suggested method for laboratory determination of shear strength of rock joint [21]. was followed to carry out the test. The constant normal load shear test was carried out at three different normal stress conditions on each sample along the dip direction (measured in the field) at a rate of $\approx 0.20-0.50 \mathrm{~mm} / \mathrm{min}$. The applied shear load was recorded at every $0.5 \mathrm{~mm}$ displacement and this continues until the

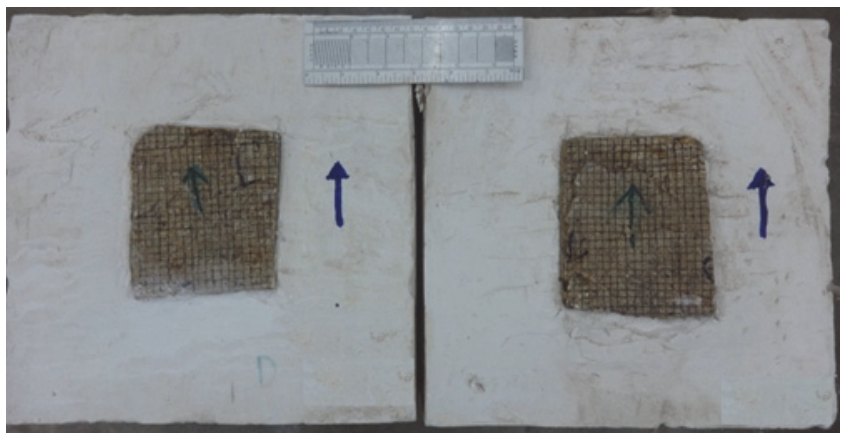

Fig.2 An Encapsulated shear sample

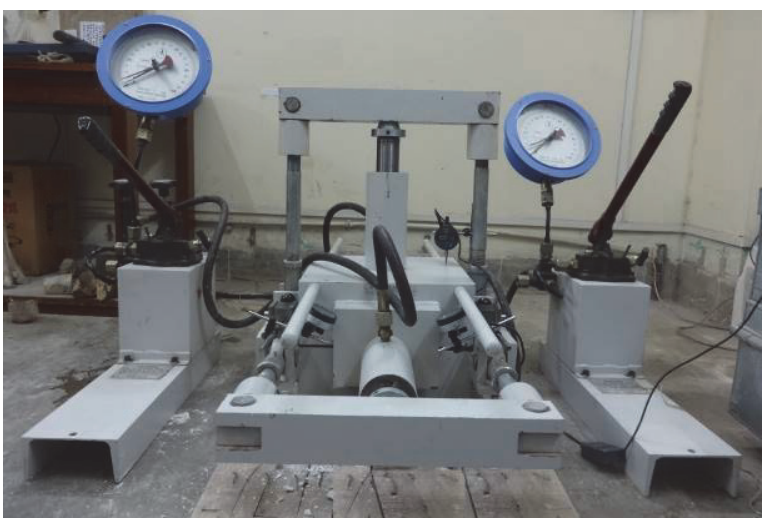

Fig.3 Direct shear test apparatus.

shearing displacement becomes $9-11 \%$ of the total length of the discontinuity surface

\section{RESUlTS AND DisSCUSSION}

The direct shear test results are illustrated graphically in Fig. 4, Fig.5and Fig.6. It should be noted that the multistage constant normal load shear tests were carried out at three different normal stress conditions in an increasing order on each sample. As shown in Fig.6, the stress ratio (i.e. $\tau / \sigma_{\mathrm{n}}$ ), also denoted as coefficient of friction, are plotted against shear displacement or horizontal displacement. The $\tau_{\mathrm{p}} / \sigma_{\mathrm{n}}$ ratio at each normal stress conditions are also plotted in Fig.4 and Fig. 5 with reference to weathering grade, i.e. W.G-II and W.G- III respectively.

From the Figures, it is clearly evident that coefficient of friction decreases with increasing normal stress irrespective of weathering grade. However, the amount of decrease in it, is depends upon the weathering state of discontinuity surface. It is also noticed that at lower normal stresses, coefficient of friction does not depend upon the weathering state of discontinuity surface, unlike higher normal stress conditions.

Based on the three consecutive direct shear tests on a particular joint surface in the same direction at different normal stress, when $\tau_{\mathrm{P}}$ is plotted against $\sigma_{\mathrm{n}}$, it is observed that peak friction angle $\left(\phi_{\mathrm{P}}\right)$ decreases as weathering intensifies. The peak friction angle varies from $28.23^{0}-29.15^{0}$ for W.G-III joint surfaces and $36.13^{0}-38.64^{0}$ for W.G-II joint surfaces. An example is shown in Fig.7. 


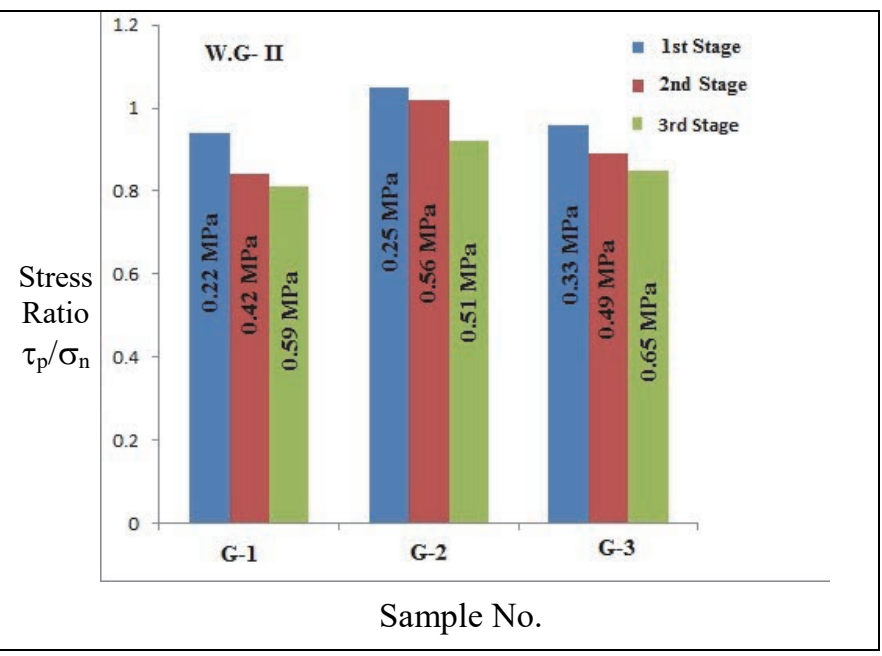

Fig.4 Stress Ratio $\left(\tau_{\mathrm{p}} / \sigma_{\mathrm{n}}\right)$ plotted at three different normal stress conditions of W.G-II rock joints

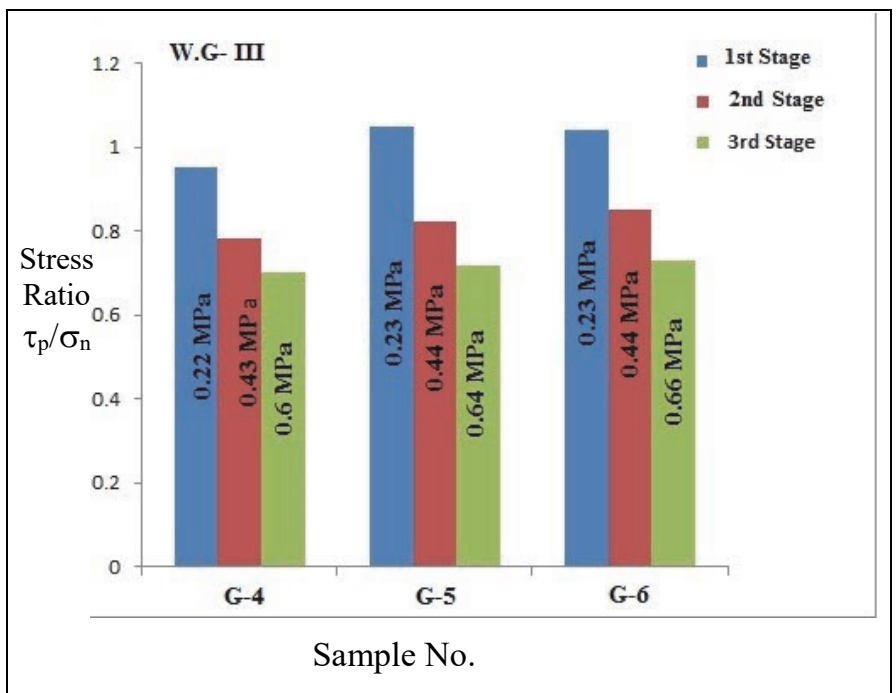

Fig.5 Stress Ratio $\left(\tau_{\mathrm{p}} / \sigma_{\mathrm{n}}\right)$ plotted at three different normal stress conditions of W.G-III rock joints

At first phase of shearing, i.e. under low normal stress conditions, sliding or overriding over the asperities (or micro asperities of planar rock joints) was the main cause of shearing resistance. This is because; the normal stresses may not be able to deform the asperities present on the rock surface.

This, in turn, results in an increase in coefficient of friction. However, with increase in normal stress, the chances to deform micro-asperities/asperities also increases, which causes a decrease in coefficient of friction and an increase in shearing resistance. Here it should be noted that the crushing of micro asperities/asperities depends upon the weathering state of discontinuity surface.

From peak friction angle estimation (i.e. plot between peak shear strength and normal stress), it is observed that weathering plays an important role in controlling the frictional resistance of rock joints.

\section{CONCLUSION}

This research dealt with the frictional resistance of natural unfilled planner rock joints with reference to weathering grade. From the study, it was evident that friction coefficient decreases with increase in normal stress, whereas frictional resistance increases. However, the increase/decrease in frictional resistance depends upon the weathering state of discontinuity surface. It was also found that peak shear strength with reference to weathering grade is more pronounced at higher normal stress conditions.

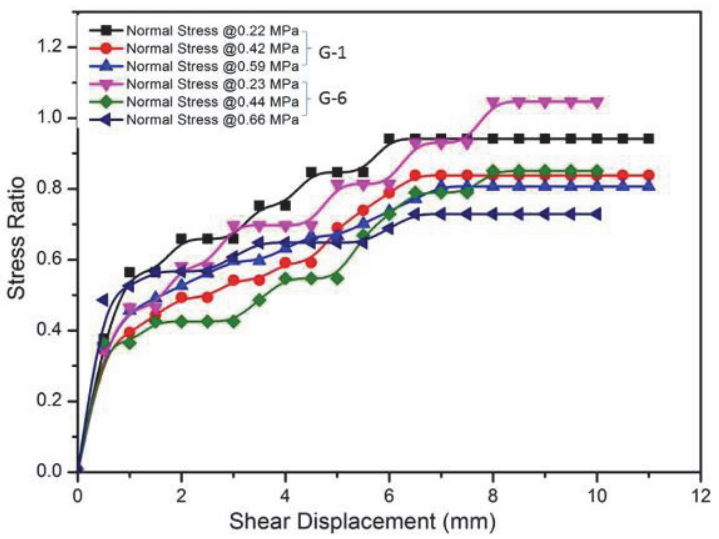

Fig.6 An example of Stress ratio- Shear displacement curve with reference to weathering grade

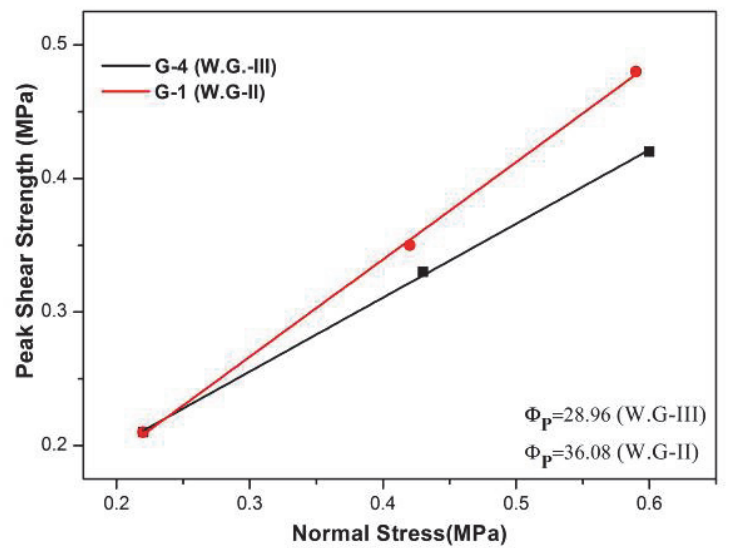

Fig.7 An example of Peak shear strength vs Normal stress plot with reference to weathering grade

[1] ReferenN. Barton, "Range of normal stress The most important factor in the shear strength of a rock joint is the," vol. 7, pp. 287-332, 19M.V. Reeves," Rock Surface Roughness and Frictional Strength". Int. J. Rock Mech. Min. Sci. \& Geomech. Abstr. Vol. 22, No. 6, pp. 429-442, 1985

[2] P. H. S. W. Kulatilake, G. Shou, T. H. Huang, , and R.M. Morgan, "New peak shear strength criteria for anisotropic rock joints". Int. J. Rock Mech. Min. Sci. and Geomech. Abstr., 32(7),pp. 673-697,1995.

[3] T. Belem, F. Homand-Etienne, and M. Souley, "Quantitative Parameters for Rock Joint Surface Roughness," Rock Mech. Rock Eng., vol. 33, no. 4, pp. 217-242, 2000.

[4] G. Grasselli and P. Egger, "Constitutive law for the shear strength of rock joints based on three-dimensional surface parameters," Int. J. Rock Mech. Min. Sci., vol. 40, no. 1, pp. 25-40, 2003. 
[5] F. Johansson, "Shear Strength of Unfilled and Rough Rock Joints in Sliding Stability Analyses of Concrete Dams," pp. 200, 2009.

[6] I. Woo, J.A Fleurisson, H.J. Park, "Influence of weathering on shear strength of joints in a porphyritic granite rock mass in Jechon area, South Korea”. Geosciences Journal Vol. 14, No. 3, pp289 - 299,2010.

[7] P. Asadollahi, F. Tonon, "Constitutive model for rock fractures: revisiting Barton's empirical model “.Eng. Geol., 113 , pp. 11-32,2010

[8] A. Usefzadeh, H. Yousefzadeh, H. Salari-rad, and M. Sharifzadeh, "Empirical and mathematical formulation of the shear behavior of rock joints," Eng. Geol., vol. 164, pp. 243-252, 2013.

[9] A. Ozvan, I.Dincer, A. Acar, B Ozvan,"The effects of discontinuity surface roughness on the shear strength of weathered granite joints". Bull Eng Geol Environ 73, pp.801-813,2014.

[10] S.R. Hencher,L.R. Richards"Assessing the shear strength of rock discontinuities at laboratory and field scales”.Rock Mech. Rock Eng., 48, pp. 883-905,2015.

[11] M. Sanei, L. Faramarzi, A. Fahimifar, S. Goli, A. Mehinrad, and A. Rahmati, "International Journal of Rock Mechanics \& Mining Sciences Shear strength of discontinuities in sedimentary rock masses based on direct shear tests," Int. J. Rock Mech. Min. Sci., vol. 75, pp. 119-131, 2015.

[12]H. K. Singh and A. Basu, "Shear behaviors of ' real' natural unmatching joints of granite with equivalent joint roughness coef fi cients," Eng. Geol., vol. 211, pp. 120-134, 2016.

[13] S. N. Sarkar, and A.K. Saha, "The present status of the Precambrian stratigraphy, tectonics and geochronology of Singhbhum-KeonjharMayurbhanj region, eastern India,'Ind. J Earth Sci.,4, pp. 37-65, 1977.

[14]ANON, " The description and classification of weathered rocks for engineering purposes,"Geological Society Engineering Group Working Party Report, Q. J. Eng. Geol., vol. 28, pp. 207-242, 1995.

[15]R. Ulusay, "The Complete ISRM Suggested Methods for Rock Characterization, Testing and Monitoring:" 1974-2006., 2007.

[16] N.O. Myers,"Characterization of surface roughness"Wear, 5, pp. 182189, 1962.

[17]X. Yu , B. Vayssade," Joint profiles and their roughness parameters". Int J Rock Mech Min Sci Geomech Abstr 28(4):pp.333-336,1991.

[18]J. Muralha, G. Grasselli, B. Tatone, M. Blümel, P. Chryssanthakis, and J. Yujing, "ISRM Suggested Method for Laboratory Determination of the Shear Strength of Rock Joints: Revised Version," Rock Mech. Rock Eng., vol. 47, no. 1, pp. 291-302, 2014 